\title{
Emerging Roles of Astrocytes in Neuro-Vascular Unit and the Tripartite Synapse With Emphasis on Reactive Gliosis in the Context of Alzheimer's Disease
}

\author{
Cai-Yun Liu ${ }^{1}$, Yu Yang ${ }^{1}$, Wei-Na Ju ${ }^{1}, X$ U Wang ${ }^{1 *}$ and Hong-Liang Zhang ${ }^{1,2 *}$ \\ ${ }^{1}$ Department of Neurology and Neuroscience Center, The First Hospital of Jilin University, Changchun, China, ${ }^{2}$ Department of \\ Life Sciences, The National Natural Science Foundation of China, Beijing, China
}

\section{OPEN ACCESS}

Edited by:

Rocío Martínez De Pablos, Universidad de Sevilla, Spain

Reviewed by: Valentyna Dubovyk, BioMed X GmbH, Germany Laura Maria Frago, Universidad Autonoma de Madrid, Spain

*Correspondence: Xu Wang sunny.uu@163.com Hong-Liang Zhang zhanghl@nsfc.gov.cn

Received: 29 April 2018 Accepted: 14 June 2018 Published: 10 July 2018

Citation:

Liu C-Y, Yang Y, Ju W-N, Wang $X$ and Zhang H-L (2018) Emerging Roles of Astrocytes in Neuro-Vascular Unit and the Tripartite Synapse With

Emphasis on Reactive Gliosis in the Context of Alzheimer's Disease. Front. Cell. Neurosci. 12:193. doi: 10.3389/fncel.2018.00193
Astrocytes, which are five-fold more numerous than neurons in the central nervous system (CNS), are traditionally viewed to provide simple structural and nutritional supports for neurons and to participate in the composition of the blood brain barrier (BBB). In recent years, the active roles of astrocytes in regulating cerebral blood flow (CBF) and in maintaining the homeostasis of the tripartite synapse have attracted increasing attention. More importantly, astrocytes have been associated with the pathogenesis of Alzheimer's disease (AD), a major cause of dementia in the elderly. Although microglia-induced inflammation is considered important in the development and progression of $A D$, inflammation attributable to astrogliosis may also play crucial roles. A1 reactive astrocytes induced by inflammatory stimuli might be harmful by up-regulating several classical complement cascade genes thereby leading to chronic inflammation, while A2 induced by ischemia might be protective by up-regulating several neurotrophic factors. Here we provide a concise review of the emerging roles of astrocytes in the homeostasis maintenance of the neuro-vascular unit (NVU) and the tripartite synapse with emphasis on reactive astrogliosis in the context of $A D$, so as to pave the way for further research in this area, and to search for potential therapeutic targets of $A D$.

\footnotetext{
Keywords: astrocytes, Alzheimer's disease, neuro-degeneration, neuro-vascular unit, synapse
}

Abbreviations: 3xTg-AD, triple transgenic animal model of Alzheimer's disease; AA, arachidonic acid; $A \beta$, amyloid beta; AD, Alzheimer's disease; ALS, amyotrophic lateral sclerosis; AQP4, aquaporin 4; ATP, adenosine triphosphate; ATPase, adenosine triphosphatase; BBB, blood brain barrier; BDNF, brain-derived neurotrophic factor; C1q, complement component 1, q subcomponent; $\mathrm{Ca}^{2+}$, calcium; CBF, cerebral blood flow; CCL, chemokine C-C motif ligand; CNS, central nervous system; CNTF, cilliary neurotrophic factor; CSF, cerebrospinal fluid; CXCL, chemokine C-X-C motif ligand; EC, entorhinal cortex; EET, epoxyeicosatrienoic acid; FGF, fibroblast growth factor; GABA, $\gamma$-aminobutyric acid; G-CSF, granulocyte colony stimulating factors; GFAP, glial fibrillary acidic protein; GLT, glutamate transporter; GM-CSF, granulocyte-macrophage colony stimulating factors; GS, glutamine synthetase; HD, Huntington's disease; IGFR, insulin-like growth factor receptor; IL, interleukin; INF, interferon; IP-10, INF- $\gamma$-induced protein 10; ISF, interstitial fluid; JAK, Janus kinase; $\mathrm{K}^{+}$, potassium; LIF, leukemia inhibitory factor; LPS, lipopolysaccharide; LTP, long-term potentiation; MCP-1, monocyte chemoattractant protein 1; MIF, macrophage migration inhibitory factor; MIP-1 $\alpha$, macrophage inflammatory protein 1 alpha; MS, multiple sclerosis; NFT, neurofibrillary tangle; NO, nitric oxide; NVU, neuro-vascular unit; PD, Parkinson's disease; PH, potential of hydrogen; PGE2, prostaglandin E2; ROS, reactive oxygen species; STAT3, signal transducer and activator of transcription 3; TGF, transforming growth factor; TNF, tumor necrosis factor; ZO-1, zonula occludens- 1 . 


\section{INTRODUCTION}

Alzheimer's disease (AD) is the leading cause of dementia in the aged population. Clinically, AD is a chronic neuro-degenerative disorder characterized by progressive decline of cognitive functions; the decline usually begins with a slight dysfunction of episodic memory, followed by a general dysfunction of overall cognitive abilities, which can affect the life quality of individuals and bring a heavy financial burden to our society (Osborn et al., 2016).

Although $\mathrm{AD}$ is generally considered to be a neuronal disease, dysfunctions of the complex interaction between various cell types in the brain are responsible for the pathogenesis of this disease. Astrocytes show a decreased expression of neuronal support and signaling genes, suggesting that astrocytes have the potential to contribute to neuronal dysfunction and cognitive decline in $\mathrm{AD}$ (Orre et al., 2014). Here we summarize the roles of astrocytes in the healthy central nervous system (CNS) and in the pathogenesis of $\mathrm{AD}$.

\section{ASTROCYTE BIOLOGY}

Neuroglia was first proposed by Virchow in 1858, which was thought to act as a kind of connective tissue in the brain and be made up of several cell types (Virchow, 1858). In 1893, the term "astrocyte," vividly describing the stellate morphology of the cells, was first proposed by Lenhossek (1893). We will first review the identification and classification of astrocytes, and their emerging roles in the neuro-vascular unit (NVU) and tripartite synapses.

\section{Identification}

There has been much debate over the identification of astrocytes (Barres, 2003, 2008; Kimelberg, 2004a,b, 2010). Among others, Kimelberg (2010) criteria are more accepted: non-excitability and a negative membrane potential determined by the trans-membrane potassium $\left(\mathrm{K}^{+}\right)$gradient are necessary but not sufficient for astrocyte identification; glycogen granule, intermediate filament bundles, $\gamma$-aminobutyric acid (GABA) and glutamate uptake by astrocyte-specific transporters, processes surrounding blood vessels and synapses and gap junctions between cells, which consist of connexins 30 and 43 are all astrocyte-specific, but not absolute.

Glial fibrillary acidic protein (GFAP) is the major intermediate filament protein in astrocytes (Liem and Messing, 2009). Up-regulation of GFAP expression is known as a sensitive and reliable marker of reactive astrocytes (Sofroniew, 2009). However, it is not a sensitive marker for astrocytes since many mature astrocytes in healthy tissue or remote from lesions express undetectable levels of GFAP (Sofroniew, 2009).

Of note is that GFAP is not exclusive to astrocytes. In the CNS, numerous cells, such as Bergmann glia of the cerebellum, tanycytes at the base of the third ventricle, pituicytes in the neurohypophysis, cribrosocytes at the optic nerve head and Müller glia in the retina, can also express GFAP (Sofroniew and Vinters, 2010). These different cell types are generally considered as part of an extended astroglial family (Sofroniew and Vinters, 2010).
Besides, pyramidal neurons of the hippocampus of $\mathrm{AD}$ patients may also express GFAP $\Delta 135$, GFAP $\Delta 164$ and GFAP $\Delta$ Ex6, which can be observed in aged controls and Down syndrome patients as well (Hol et al., 2003).

\section{Classification of Astrocytes}

As per differences in the anatomical locations and cellular morphologies, astrocytes are usually classified into two main morphological groups: the protoplasmic astrocytes throughout all the gray matter and the fibrous astrocytes throughout all the white matter (Oberheim et al., 2012). However, the diversity and complexity of cortical astrocytes contribute to one of the most distinguishing characteristics of the adult human brain (Oberheim et al., 2006). Oberheim et al. (2006, 2009) found another two distinct morphologies within the human cortex, i.e., inter-laminar astrocytes in superficial cortical layers, specific for primates and polarized astrocytes in the deep cortical layers.

\section{Astrocytes in the Neuro-Vascular Unit (NVU)}

With multiple end-feet providing almost complete coverage of the cerebral micro-vessels (Mathiisen et al., 2010), astrocytes can act as a "bridge," sensing synaptic activity and coordinating the delivery of oxygen and glucose with the metabolic requirements of nervous tissue (Belanger et al., 2011; Howarth, 2014; Figure 1A presents astrocyte functions in the NVU).

During neuronal activity, in addition to the release of nitric oxide (NO) by neurons, the calcium $\left(\mathrm{Ca}^{2+}\right)$-dependent release of vasoactive substances by astrocyte end-feet, such as prostaglandin E2 (PGE2) and epoxyeicosatrienoic acids (EETs), results in activation of $\mathrm{K}^{+}$channels in smooth muscle, evoking vasodilation and cerebral blood flow $(\mathrm{CBF})$ increase (Zonta et al., 2003; Takano et al., 2006; Attwell et al., 2010; Belanger et al., 2011). In addition to being metabolized to PGE2 or EETs within the astrocytes, arachidonic acid (AA) can alternatively diffuse to arteriole smooth muscle, and transform into the vasoconstrictor 20-hydroxyeicosatetraenoic acid (Roman, 2002; Mulligan and MacVicar, 2004; Metea and Newman, 2006).

Besides, the tight relationship between astrocytic end-feet and the vasculature is vital for the integrity of the blood brain barrier (BBB) and the homeostasis of ionic and water. Astrocytes are able to up-regulate various $\mathrm{BBB}$ features, contributing to tighter tight junctions, the expression and polarized localization of transporters, and specialized enzyme systems, which are physical barrier, transport barrier and metabolic barrier, respectively (Abbott et al., 2006; Lécuyer et al., 2016; Zenaro et al., 2017). Astrocytes play a primary role in the expression of the tight junction proteins, including occludin, claudin-5 and zonula occludens-1 (ZO-1) in the mature brain vasculature, which correlate with the induction and maintenance of the BBB integrity (Willis et al., 2004). Astrocyte membranes are abundant in aquaporin 4 (AQP4) water channels and $\mathrm{K}^{+}$transporters, as well as different kinds of proton shuttling, including mono-carboxylic acid transporters, bicarbonate transporters, the $\mathrm{Na}^{+} / \mathrm{H}^{+}$exchanger and the vacuolar-type proton adenosine tri-phosphatase (ATPase), all of which play a critical role in regulating ionic, water and 


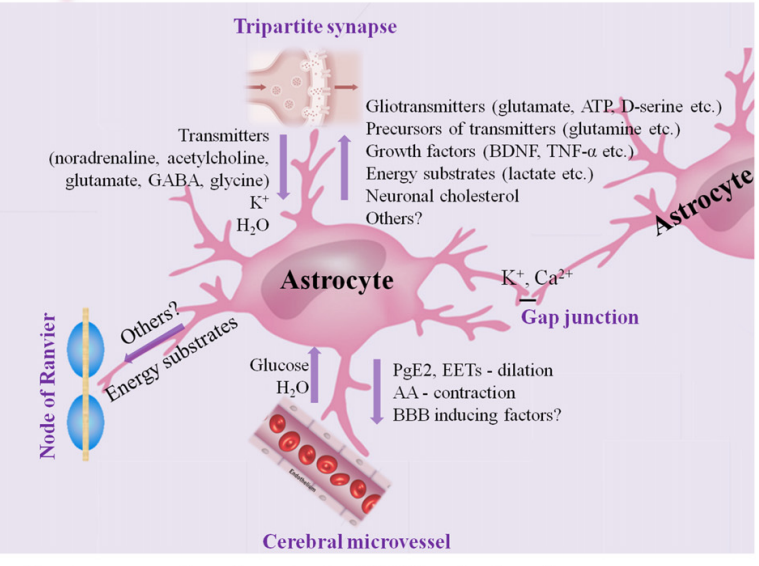

A Astrocyte functions in the NVU and tripartite synapses

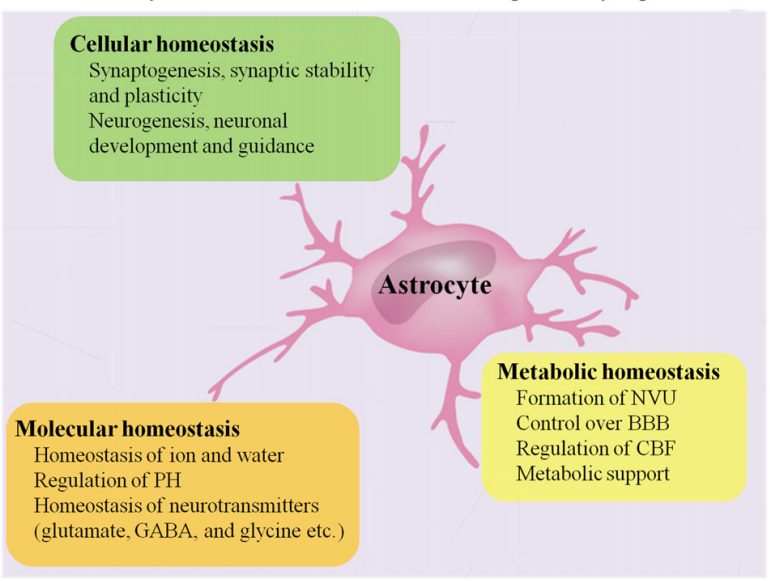

B Homeostatic functions of astrocytes

FIGURE 1 | Astrocyte functions in healthy CNS. (A) Astrocyte functions in the $\mathrm{NVU}$ and tripartite synapses. In the NVU, astrocytes gain metabolic substrates such as glucose and water from cerebral microvessel, while they can release PGE2 and epoxyeicosatrienoic acids (EETs) to evoke vasodilation and blood flow increase and release arachidonic acid (AA) to induce vasocontraction. Close apposition of astrocytic end-feet with the vasculature is vital for BBB. In the tripartite synapses, astrocytes express ionotropic and metabotropic membrane receptors, which can be activated by neuro-transmitters (such as noradrenaline, acetylcholine and glutamate) released from the pre-synaptic cleft, allowing them to sense the intensity of synaptic activity and modulate synaptic function in turn. Astrocytes participate in the spatial regulation of extracellular $\mathrm{K}^{+}$to control the ionic environment of neuropil, another way to modulate neuronal signaling. $\mathrm{Ca}^{2+}$-dependent release of gliotransmitters (such as glutamate, ATP and D-serine) allows astrocytes to control the synaptic activity. Astrocyte processes are rich in transporters for neuro-transmitters, including glutamate, GABA and glycine, serving to clear the neuro-transmitters from the synaptic space. Then, the neuro-transmitters taken into astrocytes are converted by enzymes into precursors such as glutamine, recycling back to synapses and reconverting into active transmitters. In addition, astrocytes have the potential to impose powerful and long-term impact on synaptic function by releasing growth factors and related molecules, such as brain-derived neurotrophic factor (BDNF) and TNF- $\alpha$. Astrocytes have emerged as vital players in the production, delivery, storage and utilization of the brain energy. Lactate synthesized by astrocytes is released to the extracellular space, then taken up by neurons and oxidized to provide energy. Moreover, astrocytes are the main producers of neuronal cholesterol, which is an essential component of membranes and the precursor for many vital signaling molecules. They can also provide energy substrates to the nodes of

(Continued)
FIGURE 1 | Continued

Ranvier. Finally, astrocytes are interconnected into functional networks via gap junctions. (B) Homeostatic functions of astrocytes. Astrocytes play multiple essential roles in the maintenance of cellular, molecular and metabolic homeostasis. ATP, adenosine triphosphate; BBB, blood brain barrier; CNS, central nervous system; GABA, $\gamma$-aminobutyric acid; NVU, neuro-vascular unit; PGE2, prostaglandin E2; TNF, tumor necrosis factor.

potential of hydrogen $(\mathrm{PH})$ homeostasis (Sofroniew and Vinters, 2010). An astrocytic AQP4-dependent anatomical pathway called "glymphatic" system promotes the exchange of interstitial fluid (ISF) and cerebro-spinal fluid (CSF) and the clearance of interstitial solutes, such as amyloid $\beta$ (A $\beta$; Iliff et al., 2012).

\section{Astrocytes in the Tripartite Synapses}

Astrocytes, together with presynaptic and postsynaptic nerve terminals, form "tripartite" complexes (Araque et al., 1999). Peri-synaptic processes of astrocytes can modulate the stabilization, dynamics and maturation of dendritic spines, and participate in the modulation of synaptic transmission and plasticity (Ullian et al., 2001; Haber et al., 2006; Nishida and Okabe, 2007; Rossi, 2015; Figure 1A presents astrocyte functions in the tripartite synapses).

Astrocytes express ionotropic and metabotropic membrane receptors, which can be activated by neuro-transmitters (for instance, noradrenaline, acetylcholine and glutamate) released from the pre-synaptic cleft, allowing them to sense the intensity of synaptic activity and modulate synaptic function in turn (Verkhratsky and Nedergaard, 2014). In this process, transient increase of astrocytic intra-cellular $\mathrm{Ca}^{2+}$ levels, the degree of which is dependent on the intensity of neuronal activity, triggers the selective release of various glio-transmitters (for instance, adenosine triphosphate (ATP), glutamate and D-serine) to individual synaptic inputs, offering multiple ways of controlling synaptic activity (Dani et al., 1992; Nedergaard, 1994; Parpura et al., 1994; Porter and McCarthy, 1996; Pasti et al., 1997; Araque et al., 1998, 2014; Fellin et al., 2004; Perea and Araque, 2007; Henneberger et al., 2010; Di Castro et al., 2011; Min and Nevian, 2012; Navarrete et al., 2012; Khakh and McCarthy, 2015; Rusakov, 2015).

In addition, spontaneous $\mathrm{Ca}^{2+}$ oscillation, intrinsic signaling detected in a subpopulation of astrocytes, is independent of neuronal activity and may also be involved in modulating neuronal activity (Nett et al., 2002). Up-regulation of astrocytic $\mathrm{Ca}^{2+}$ has a direct influence on synapses (synaptic integrity and plasticity, the release of glio-transmitters) and circuit transmission (sensory plasticity and network synchronization; Guerra-Gomes et al., 2018). Moreover, astrocytes can remove synaptically released excitatory and inhibitory neurotransmitters known as glutamate and GABA respectively, the speed of which affects the intensity of post-synaptic activation, serving to further regulate signal transmission (Arnth-Jensen et al., 2002; Schousboe et al., 2004). Astrocytes take part in the spatial regulation of extracellular $\mathrm{K}^{+}$to control the ionic environment of neuropil, another way to modulate neuronal signaling (Halassa and Haydon, 2010). Astrocytes are also capable of imposing powerful and long-term impact on synapses 
by releasing growth factors and related molecules, including brain-derived neurotrophic factor (BDNF) and tumor necrosis factor- $\alpha$ (TNF- $\alpha$; Sofroniew and Vinters, 2010).

Astrocytes are inter-connected into functional networks via gap junction channels and simultaneously integrate information from the neurons and beyond the synapses, such as from microglia and vascular cells, modulating the complex neurotransmission within a dynamic micro-environment finely (Giaume et al., 2010). Interestingly, the transplant-derived human glia progenitor cells were gap-junction-coupled to astrocytes of host mouse and show some human-like physiological properties, for example, propagating $\mathrm{Ca}^{2+}$ signals three-fold faster than their hosts resulting in enhanced long-term potentiation (LTP) and memory and learning functions of the transplanted mice (Han et al., 2013).

Astrocytes in the tripartite synapses also play an essential role in the homeostasis of transmitters (Sofroniew and Vinters, 2010). Astrocyte processes are rich in transporters for neurotransmitters, including glutamate, glycine and GABA, serving to remove the neuro-transmitters from the synaptic cleft (Sofroniew and Vinters, 2010). Then, the neuro-transmitters taken into astrocytes are converted by enzymes into precursors, such as glutamine, recycling back to synapses and reconverting into active transmitters (Sofroniew and Vinters, 2010). In this way, astrocytes also play a protective role by maintaining a sufficiently low level of extra-synaptic glutamate to prevent excitotoxicity (Schousboe et al., 2004), and releasing anti-oxidants such as glutathione to protect neurons from oxidative stress (Chen et al., 2001, 2009; Shih et al., 2003; Vargas et al., 2008).

Astrocytes have emerged as vital players in the production, delivery, storage and utilization of the brain energy including glucose, as well as its metabolic intermediates, such as lactate, ketone bodies, glutamate and pyruvate (Zielke et al., 2009; van Hall et al., 2009; Belanger et al., 2011; Patel et al., 2014; Magistretti and Allaman, 2015; Camandola and Mattson, 2017; Clasadonte et al., 2017; Liu et al., 2017).

Moreover, astrocytes are the main producers of neuronal cholesterol, which is an essential component of membranes and the precursor for many vital signaling molecules (Pfrieger and Ungerer, 2011; Zhang and Liu, 2015).

In summary, astrocytes are highly differentiated cells that play several essential roles in the healthy CNS, including maintenance of the homeostasis of fluid, ions and transmitters, regulation of $\mathrm{CBF}$, participation in synaptic plasticity and functions, and provision of energy substrates to neurons (Figure 1). Increasing evidences indicate that astrocytes participate in regulation of advanced brain functions, including coordinating fine motor (Saab et al., 2012), controlling the sleep-wake cycle (Ding et al., 2016; Brancaccio et al., 2017), regulating memory (Orr et al., 2015), modulating depressive-like behaviors (Cao et al., 2013; Wang et al., 2017; Yang et al., 2018) and influencing ageing rate (Yin et al., 2017). In response to various forms of insults including ischemia, trauma, infections and neurodegenerative diseases such as $\mathrm{AD}$, astrocytes undergo extensive cellular, molecular and functional changes whereby losing normal functions or gaining detrimental effects. Herein, we will focus on the emerging role of astrocytes in $\mathrm{AD}$.

\section{ASTROCYTES IN ALZHEIMER'S DISEASE}

$\mathrm{AD}$ is histo-pathologically characterized by the presence of senile plaques with $A \beta$ aggregates, intracellular neurofibrillary tangles (NFTs) with hyper-phosphorylated tau and activated glial cells surrounding senile plaques (Serrano-Pozo et al., 2013). Both astrogliosis and atrophic/asthenic changes of astrocytes (termed "astro-degeneration") occur, and often precede the formation of specific histopathology, including plaques and NFTs (Heneka et al., 2005; Verkhratsky et al., 2010, 2014, 2016; Orre et al., 2014; Figure 2 presents astrogliosis and astro-degeneration in $\mathrm{AD}$ ). We then focus on how astrogliosis and astro-degeneration occur and their roles in $\mathrm{AD}$.

\section{Astrogliosis}

Gliosis, including the activation and often proliferation of glial cells, is a non-specific phenomenon observed in neurodegenerative diseases and brain injury. There is increasing recognition that reactive astrocytes are vital and central responders to CNS injury and disease, but there is no widely accepted definition of reactive astrogliosis. A definition of astrogliosis encompassing four interdependent key features has been proposed by Sofroniew (2009): (1) astrocytes respond to CNS insults including subtle perturbations and a series of changes occur; (2) a gradated continuum of progressive changes in molecular expression and progressive cellular hypertrophy may occur depending on the intrinsic quality and severity of the insult, and in severe cases, proliferation and scar formation may be initiated; (3) the changes undergone during reactive astrogliosis are regulated by inter- and intra-cellular signaling molecules in a context-specific manner; and (4) surrounding neurons and non-neural cells may be influenced by the altered activities of astrocytes following astrogliosis. Taken together, astrogliosis can be defined as a finely gradated continuum of progressive cellular and molecular changes in astrocytes. Reactive astrocytes exhibit lots of molecular and morphological characteristics. As discussed above, most if not all reactive astrocytes are GFAP positive, while some astrocytes express undetectable levels of GFAP in healthy CNS tissue or remote from lesions. Up-regulation of GFAP, as well as up-regulation of vimentin and synemin, reexpression of nestin and hypertrophy of astrocytes, is viewed as a marker of astrogliosis.

Liddelow et al. (2017) proposed that neuro-inflammation and ischemia induced two distinct types of reactive astrocytes termed "A1" and "A2" respectively. A1s are highly present in many neuro-degenerative diseases, including $\mathrm{AD}$, as well as Parkinson's disease (PD), Huntington's disease (HD), amyotrophic lateral sclerosis (ALS) and multiple sclerosis (MS). Several classical complement cascade genes are up-regulated in A1 astrocytes, which have been demonstrated to be destructive to synapses (Stevens et al., 2007). A1 cells lose the ability to promote the survival and outgrowth of neurons and to promote synaptogenesis and to phagocytize debris of synapses and myelin, secrete a still unclear neurotoxin, and finally drive death of neurons and oligodendrocytes. By contrast, A2 cells induced by ischemia have the potential to up-regulate many neurotrophic 


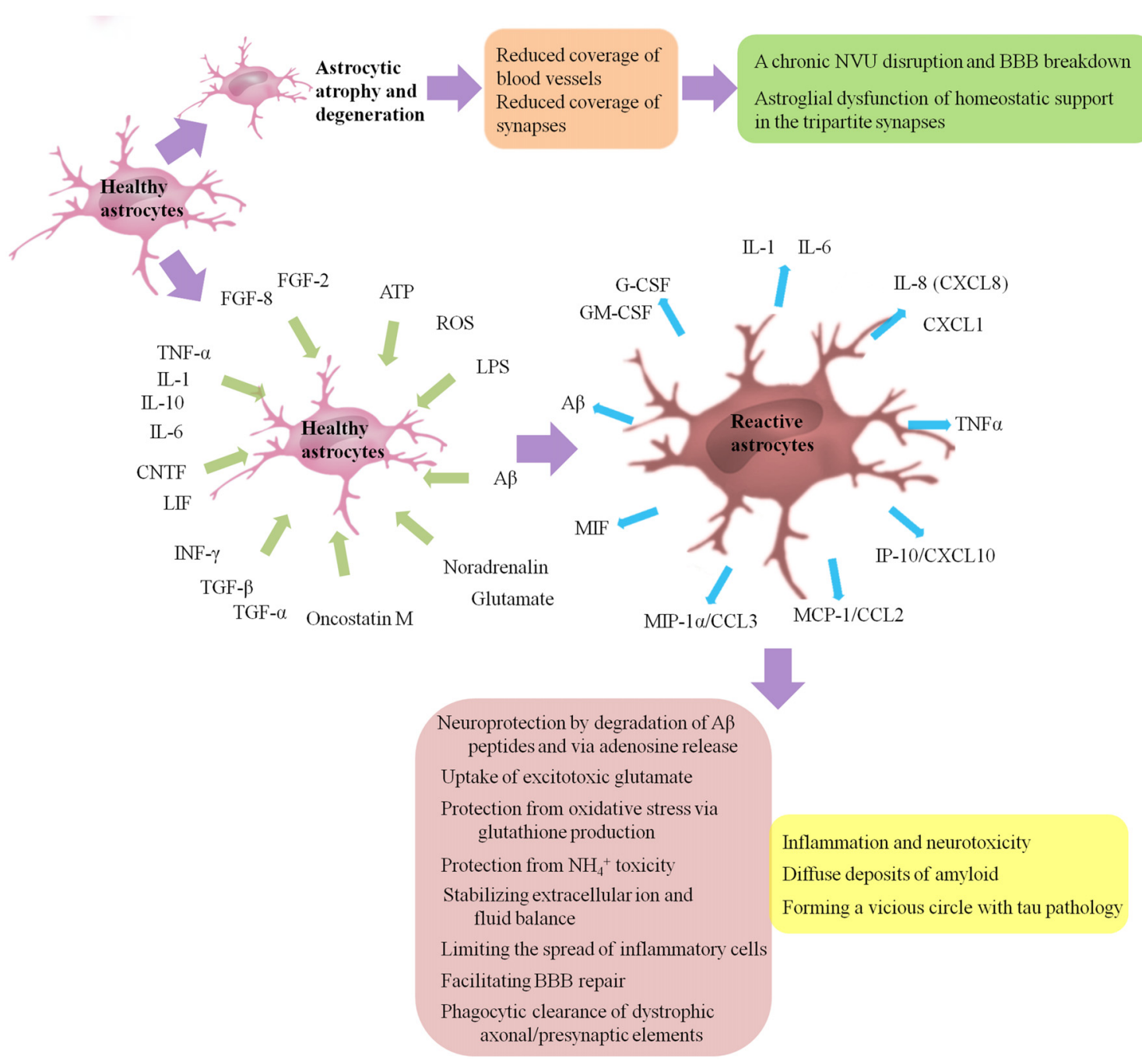

FIGURE 2 | Astrogliosis and astro-degeneration in AD. Astrocytes undergo differential pathological alterations, depending on the stage of the disease, their relation to $A \beta$ plaques and distinct brain regions. Both astrogliosis and astro-degeneration occur in AD, and often precede the formation of specific histopathology. First, at the early stages of AD, astrocytes in EC, prefrontal cortex and hippocampus exhibit features of atrophy and degeneration, reduction in volume of GFAP-positive profiles, surface area and morphological complexity. Astroglial atrophy and degeneration most likely lead to a reduction in the astroglial coverage of blood vessels and synapses, contributing to dysfunction in the NVU and tripartite synapses. Second, astrogliosis is a finely gradated continuum of progressive alterations in gene expression and cellular changes, which may be triggered or regulated by many various intercellular signaling molecules, including IL-1, IL-6, IL-10, TNF- $\alpha$, INF- $\gamma$, CNTF, LIF, oncostatin M, FGF-2, FGF-8, TGF- $\alpha$, TGF- $\beta$, A $\beta$, LPS, ATP, ROS, noradrenalin and glutamate. Activated astrocytes may secrete many cytokines and chemokines, such as IL-1, IL-6, TNF- $\alpha$, CXCL1, IL-8 (CXCL8), IP-10/CXCL10, MCP-1/CCL2, MIP-1 $\alpha / C C L 3$, MIF, G-CSF and GM-CSF, causing the infiltration of circulating leukocytes into the brain and leading to a chronic inflammatory process. Besides, reactive glial cells are closely associated with diffuse deposits of $A \beta$. $A$ normal process of astrogliosis exerts beneficial functions, including: neuroprotection by degradation of $A \beta$ peptides and via adenosine release; uptake of excitotoxic glutamate; protection from oxidative stress via glutathione production and protection from $\mathrm{NH}_{4}{ }^{+}$toxicity; stabilizing extracellular ion and fluid balance; limiting the spread of inflammatory cells; facilitating BBB repair; phagocytic clearance of dystrophic axonal/presynaptic elements. Pathologically aggregated tau is also closely associated with gliosis. On one hand, tau pathology is capable to promote microglial and astrocytic activations. On the other hand, activation of microglia/astrocytes and associated pro-inflammatory cytokines such as TNF promote tau pathology in turn, forming a vicious circle. A $\beta$, amyloid- $\beta$; AD, Alzheimer's disease; ATP, adenosine triphosphate; CNTF, cilliary neurotrophic factor; CCL, chemokine C-C motif ligand; CXCL, chemokine C-X-C motif ligand; EC, entorhinal cortex; FGF, fibroblast growth factor; G-CSF, granulocyte colony stimulating factor; GFAP, glial fibrillary acidic protein; GM-CSF, granulocyte-macrophage colony stimulating factors; IL, interleukin; INF- $\gamma$, interferon- $\gamma$; IP-10, INF- $\gamma$-induced protein 10; LIF, leukemia inhibitory factor; LPS, lipopolysaccharide; MCP-1, monocyte chemoattractant protein 1; MIF, macrophage migration inhibitory factor; MIP-1 $\alpha$, macrophage inflammatory protein 1 alpha; ROS, reactive oxygen species; TGF, transforming growth factor; TNF- $\alpha$, tumor necrosis factor- $\alpha$.

factors and thrombospondins, which promote survival and growth of neurons and promote synapse repair, respectively.

Many intercellular signaling molecules have the potential to trigger or regulate reactive astrogliosis. A number of cytokines and growth factors (Balasingam et al., 1994; John et al., 2003; Cregg et al., 2014), including interleukin (IL)-1, IL-6 (Klein et al., 1997; Hostenbach et al., 2014), TNF- $\alpha$ (Rabchevsky et al., 1998), interferon (INF)- $\gamma$ (Yong et al., 1991), leukemia inhibitory 
factor (LIF), cilliary neurotrophic factor (CNTF; Winter et al., 1995), oncostatin M (Sriram et al., 2004), fibroblast growth factor (FGF)-2, FGF-8 (Kang K. et al., 2014), transforming growth factor (TGF) $-\alpha$ and TGF- $\beta$, have been shown able to activate astrocytes. $A \beta$, as well as mediators of innate immunity such as lipopolysaccharide (LPS), purines such as ATP, neurotransmitters such as noradrenalin and glutamate, and molecules of oxidative stress such as reactive oxygen species (ROS), also has the potential to regulate astrogliosis (Sofroniew, 2009). There is some debate about whether FGFs promote or suppress the activation of astrocytes (Eclancher et al., 1990; Menon and Landerholm, 1994; Reilly and Kumari, 1996; Reilly et al., 1998; Clarke et al., 2001; Goddard et al., 2002; Kang W. et al., 2014; Kang K. et al., 2014; Hizay et al., 2016), which needs further research.

In response to various forms of CNS insults, such mediators of astrogliosis could be released by any cell types in CNS, such as other astrocytes, oligodendrocyte lineage cells, neurons, microglia, leukocytes, endothelia and pericytes (Sofroniew, 2009). It was recently demonstrated, in vitro and in vivo, that activated microglia, which were insufficient to kill neurons by themselves, could strongly induce A1s by secreting IL- $1 \alpha$, TNF- $\alpha$ and complement component 1 , q subcomponent (C1q), which together were sufficient and necessary (Liddelow et al., 2017). Future studies should focus on the question what the neurotoxin secreted by A1s is, and on new drugs which are potential to treat various $\mathrm{CNS}$ diseases including $\mathrm{AD}$ by preventing $\mathrm{A} 1$ formation, promoting A1 reversion, or blocking the neurotoxin, and on whether available drugs approved to inhibit human IL- $1 \alpha$ and TNF- $\alpha$ could be applied on AD. Interestingly, CCR2-/mice with reduced monocyte invasion show strong increased astrocyte proliferation but reduced scar formation (Frik et al., 2018). Further studies should focus on the signaling pathways underlying the adverse effects of monocyte invasion.

The regulatory mechanisms of astrogliosis remain elusive. Dramatically, transcriptomic analysis shows that gene expression of reactive astrocytes varies depending upon the stimulus (Zamanian et al., 2012). Accordingly, the specific contexts of stimuli induce different morphological, molecular and functional alterations in reactive astrocytes via distinct inter- and intracellular signaling pathways, which is relevant to various roles of astrocytes playing in different pathological states (Sofroniew, 2009). The diverse signaling pathways associated with signal transducer and activator of transcription 3 (STAT3), NF-кB, cAMP, Rho-kinase, JNK, Olig2, CEPB1 and EphB2 are involved in mediating different aspects or different degrees of astrogliosis, including cell hypertrophy, proliferation, migration and scar formation as well as up-regulation of GFAP, vimentin and nestin (Sofroniew, 2014). Among these signaling pathways, the Janus kinase (JAK)-STAT3 pathway is a crucial inducer of astrocyte reactivity in various pathological conditions in the CNS

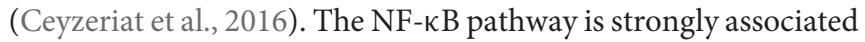
with neuro-inflammation and neuro-degenerative diseases and can be activated by numerous pro-inflammatory agents, such as cytokines, viral or bacterial antigens, $A \beta$ and free radicals (Liddelow and Barres, 2017). In addition to NF- $\mathrm{B}$ activation, complement protein $\mathrm{C} 3$ (a marker of A1 astrocytes) can be activated by $\mathrm{A} \beta$ in brain tissue from APP transgenic mice and AD patients (Lian et al., 2015). Moreover, it has been shown that $\beta 1$-integrin-mediated signaling is essential for the procurement of mature, non-reactive astrocytes and, therefore, alterations of this signaling pathway may be implicated in eliciting reactive astrogliosis (Robel et al., 2009). A recent research in mice has shown that active ErbB signaling is able to stimulate many intracellular signals crucial for astrogliosis, including STAT3 and is sufficient to initiate reactive responses of mature astrocytes, prompting characterized morphological and molecular features of injury- and/or disease-induced astrogliosis (Chen et al., 2017).

The overall process of astrogliosis was initially viewed as a maladaptive and negative phenomenon, contributing to inflammation and neurotoxicity. Astrocytes may secrete many cytokines and chemokines, such as IL-1, IL-6, chemokine C-X-C motif ligand (CXCL)-1, IL-8 (CXCL8), INF- $\gamma$-induced protein 10 (IP-10/CXCL10), TNF- $\alpha$, monocyte chemoattractant protein 1 (MCP-1/chemokine C-C motif ligand (CCL2)), macrophage inflammatory protein 1 alpha (MIP-1 $\alpha /$ CCL3), macrophage migration inhibitory factor (MIF), granulocyte-macrophage colony stimulating factors (GM-CSF) and granulocyte colony stimulating factors (G-CSF), causing the infiltration of circulating leukocytes into the brain and leading to a chronic inflammatory process, which can be promoted by activated perivascular microglial cells (Liebner et al., 2018). The persistent activation of glial cells and associated inflammation may be part of the neuro-inflammatory neurotoxic response (Wyss-Coray, 2006; Lian et al., 2015; Kawano et al., 2017) and associated with the progression of AD (Nagele et al., 2004; Osborn et al., 2016).

Increasing evidences have shown that a normal process of astrogliosis exerts positive effects, including (Sofroniew and Vinters, 2010; Gomez-Arboledas et al., 2018): (1) neuroprotection by degradation of $A \beta$ peptides and via adenosine release; (2) protection against oxidative stress via producing glutathione and protection from $\mathrm{NH}_{4}{ }^{+}$toxicity; (3) excitotoxic glutamate uptake; (4) stabilizing extracellular ion and fluid balance; (5) limiting the spread of inflammatory cells; (6) facilitating BBB repair; and (7) phagocytic clearance of dystrophic axonal/presynaptic elements. A recent study on post-mortem brains obtained from bodies of $\mathrm{AD}$ patients aged over 70 years at death showed that reactive astrocytes with enhanced glutamate transporter (GLT)-1 expression may protect neurons and synaptic transmission from the neurotoxicity due to $\mathrm{A} \beta$ and NFT deposition, and then help to maintain cognitive function despite the progression of $\mathrm{AD}$ neuro-pathological alterations (Kobayashi et al., 2018).

Concerning $A \beta$, reactive glial cells are strongly related with $A \beta$ plaque formation or diffuse deposits of $A \beta$ (Nagele et al., 2004). Meanwhile, activated microglia and reactive astrocytes surrounding $A \beta$ plaques are also regarded as an endogenous defense mechanism against plaque deposition in AD (Wyss-Coray et al., 2003; Koistinaho et al., 2004; Condello et al., 2015). Pathologically aggregated tau, another histopathological hallmark of $\mathrm{AD}$, is also closely associated with gliosis. There is a co-localization between tau oligomers and activated microglia/astrocytes, which has been demonstrated in both tauopathy mice and AD patients (Sasaki et al., 2008; 
Nilson et al., 2017). On one hand, tau pathology is capable to promote microglial and astrocytic activation. Several studies on tau transgenic mice have demonstrated that significant astrogliosis (Laurent et al., 2017), as well as microgliosis and synapse loss (Bellucci et al., 2004; Yoshiyama et al., 2007), is spatio-temporally associated with hippocampal tau pathology. In the context of tau pathology, $\mathrm{T}$ cell infiltration may directly regulate the activation status of microglia and/or astrocytes, exerting passive influence on synaptic plasticity (Laurent et al., 2017). In vitro, misfolded truncated tau protein may activate microglia and induce the release of pro-inflammatory cytokines (TNF- $\alpha$, IL-1 $\beta$, IL-6) and NO via MAPK pathways (Kovac et al., 2011). On the other hand, activation of microglia/astrocytes and associated pro-inflammatory cytokines such as TNF- $\alpha$ promote tau pathology in turn (Gorlovoy et al., 2009; Maphis et al., 2015; Laurent et al., 2018), forming a vicious circle. Furthermore, in vitro (Calafate et al., 2015; Takeda et al., 2015) and in vivo (de Calignon et al., 2012; Liu et al., 2012; Kaufman et al., 2017; Narasimhan et al., 2017; DeVos et al., 2018) studies have provided evidence that tau aggregates have the ability to spread along the synaptically connected networks. In the tripartite synapses, tau may contribute to the dysfunction of neurons and synapses due to reduced density of dendritic spines, deterioration of axon initial segments, impairment of axonal transport and reduced mobility of presynaptic vesicles (Tracy and Gan, 2018). Truncated tau may also have the potential to exacerbate $\mathrm{BBB}$ deterioration, featured by an increase of mannitol permeability and a decrease of trans-endothelial electrical resistance, which may be regulated by chemokines and pro-inflammatory cytokines released by activated microglia and astrocytes, such as MCP-1 and TNF- $\alpha$ (Kovac et al., 2009). Blair et al. (2015) demonstrated in a tauopathy mouse model that tau aggregation alone was sufficient for BBB damage. Notably, the integrity of the $\mathrm{BBB}$ may recover when the levels of perivascular tau are reduced, suggesting that therapies targeting tau can alleviate the vascular involvement of tauopathies by maintaining BBB integrity (Blair et al., 2015).

\section{Astro-degeneration}

Antibodies against GFAP, a component of a cyto-skeleton, as well as antibodies against $\mathrm{S} 100 \beta$ and glutamine synthetase (GS), two kinds of cytosolic proteins, are commonly used to identify the morphological appearance of astrocytes. In post-mortem tissues of family $\mathrm{AD}$ patients, atrophic astrocytes have been found (Rodríguez-Arellano et al., 2016). Meanwhile, studies in the triple transgenic animal model of $\mathrm{AD}$ (3xTg$\mathrm{AD})$ have demonstrated that astrocytes undergo differential pathological alterations, depending on the stage of the disease, their relation to $\mathrm{A} \beta$ plaques and distinct brain regions. First, at the early stages of $\mathrm{AD}$, astrocytes in entorhinal cortex (EC), pre-frontal cortex and hippocampus exhibited features of atrophy and degeneration, reduction in the morphological complexity, surface area and volume of GFAP-positive profiles, which was observed in $3 \times \mathrm{Tg}-\mathrm{AD}$, as well as in another model of AD, the PDAPP-J20 trans-genic mice (Beauquis et al., 2013, 2014). In the $3 \times$ Tg-AD mice, the atrophic changes appeared much later in the hippocampus than in EC, at the age of 6 months and 1 month respectively, while at the age of 3 months these alterations became significant in the prefrontal cortex (Olabarria et al., 2010; Yeh et al., 2011; Kulijewicz-Nawrot et al., 2012). Conversely, astrocytes surrounding plaques showed obviously hypertrophic characteristics, including increased surface and volume of GFAP-positive profiles (Olabarria et al., 2010). Finally, GS expression and the amount of astrocytes expressing GS in the hippocampus and prefrontal cortex were significantly decreased (Olabarria et al., 2011; Kulijewicz-Nawrot et al., 2013), while GS levels remained stable in EC (Yeh et al., 2013). However, the density of astrocytes was impacted neither by age nor by AD (Olabarria et al., 2010). Insulin-like growth factor receptor (IGFR) signaling may be essential to regulate mitochondrial metabolism and $A \beta$ uptake in astrocytes. Age-related astrocytic dysfunction caused by IGFR signaling deficiency may contribute to the pathogenesis of $\mathrm{AD}$, as well as other age-associated cognitive disorders (Logan et al., 2018). Altered astrocytic expression of AQP4 and GLT-1 results in the disruption of water and glutamate homeostasis, which may be associated with the progressive neuro-degeneration in $\mathrm{AD}$ (Hoshi et al., 2018). Further studies are needed to explore the mechanism how astro-degeneration occurs and the signaling pathways by which astro-degeneration works in the pathogenesis of $\mathrm{AD}$.

Astroglial atrophy and degeneration most likely lead to a decrease in the astroglial envelope of cerebral vessels and synapses, contributing to dysfunction in the NVU and tripartite synapses. Within the NVU, the reduction of end-feet coverage of cerebral microvessels results in the vascular deficits as observed at the early stages of AD (Montagne et al., 2015, 2017; Zhao et al., 2015; van de Haar et al., 2016a,b; Sweeney et al., 2018). Experimental studies in transgenic mice have shown that aberrant astrocyte-pericyte signaling leads to a chronic NVU disruption and BBB break-down, contributing to accumulation of circulating neurotoxic molecules including hemoglobin, thrombin, fibrinogen, free iron, hemosiderin and/or plasmin in the CNS, particularly in neurons, as well as faulty clearance of neurotoxic molecules from brain, inappropriate delivery of energy metabolite, and abnormal expression of matrix molecules, vascular receptors and growth factors, all of which may initiate and/or eventually result in neuro-degeneration (Zlokovic, 2008; Ryu and McLarnon, 2009; Hultman et al., 2013; Sengillo et al., 2013; Zhao et al., 2015; Nelson et al., 2016). As discussed above, astrocytes play essential roles in the tripartite synapses, including supply of energy, regulation of synaptic plasticity and transmission and maintenance of the homeostasis of transmitters. Then, astro-degeneration may directly contribute to astroglial dysfunction of homeostatic support in the tripartite synapses, leading to dwindling synaptic contacts, weakening synaptic plasticity and affecting synaptic transmission (Coleman et al., 2004).

Taken together, astrogliosis as well as astro-degeneration, alone or in combination, is the essential component of $\mathrm{AD}$. Further studies on the involvement of astrocytes in the pathogenesis of $\mathrm{AD}$, interaction between astrocytes and other cell types in CNS, and the underlying mechanisms are critical for advancing new therapeutic targets. 


\section{CONCLUSION}

Healthy astrocytes play multiple vital roles in maintaining and regulating synaptic physiology, neuronal communication and energy metabolism, whereas astrogliosis and astro-degeneration contribute to the pathogenesis and progression of $\mathrm{AD}$ via both loss of these normal functions and gain of several toxic effects. Astrogliosis are closely associated with formation of $\mathrm{A} \beta$ plaques and tau and contributes to inflammation and neurotoxicity and as well have beneficial functions in an appropriate process. Astrodegeneration may directly contribute to astroglial dysfunction of homeostatic support in the NVU and tripartite synapses, leading to a chronic NVU disruption, BBB breakdown and synaptic dysfunction. Further studies should focus on the underlying mechanism of multifaceted functions of astrocytes and novel therapeutic strategies for AD.

\section{REFERENCES}

Abbott, N. J., Rönnbäck, L., and Hansson, E. (2006). Astrocyte-endothelial interactions at the blood-brain barrier. Nat. Rev. Neurosci. 7, 41-53. doi: $10.1038 / \mathrm{nrn} 1824$

Araque, A., Carmignoto, G., Haydon, P. G., Oliet, S. H., Robitaille, R., and Volterra, A. (2014). Gliotransmitters travel in time and space. Neuron 81, 728-739. doi: 10.1016/j.neuron.2014.02.007

Araque, A., Parpura, V., Sanzgiri, R. P., and Haydon, P. G. (1999). Tripartite synapses: glia, the unacknowledged partner. Trends Neurosci. 22, 208-215. doi: 10.1016/s0166-2236(98)01349-6

Araque, A., Sanzgiri, R. P., Parpura, V., and Haydon, P. G. (1998). Calcium elevation in astrocytes causes an NMDA receptor-dependent increase in the frequency of miniature synaptic currents in cultured hippocampal neurons. J. Neurosci. 18, 6822-6829. doi: 10.1523/JNEUROSCI.18-17-06822. 1998

Arnth-Jensen, N., Jabaudon, D., and Scanziani, M. (2002). Cooperation between independent hippocampal synapses is controlled by glutamate uptake. Nat. Neurosci. 5, 325-331. doi: 10.1038/nn825

Attwell, D., Buchan, A. M., Charpak, S., Lauritzen, M., Macvicar, B. A., and Newman, E. A. (2010). Glial and neuronal control of brain blood flow. Nature 468, 232-243. doi: 10.1038/nature09613

Balasingam, V., Tejada-Berges, T., Wright, E., Bouckova, R., and Yong, V. W. (1994). Reactive astrogliosis in the neonatal mouse brain and its modulation by cytokines. J. Neurosci. 14, 846-856. doi: 10.1523/JNEUROSCI.14-0200846.1994

Barres, B. A. (2003). What is a glial cell? Glia 43, 4-5. doi: 10.1002/glia.10252

Barres, B. A. (2008). The mystery and magic of glia: a perspective on their roles in health and disease. Neuron 60, 430-440. doi: 10.1016/j.neuron. 2008.10.013

Beauquis, J., Pavia, P., Pomilio, C., Vinuesa, A., Podlutskaya, N., Galvan, V., et al. (2013). Environmental enrichment prevents astroglial pathological changes in the hippocampus of APP transgenic mice, model of Alzheimer's disease. Exp. Neurol. 239, 28-37. doi: 10.1016/j.expneurol.2012.09.009

Beauquis, J., Vinuesa, A., Pomilio, C., Pavia, P., Galván, V., and Saravia, F. (2014). Neuronal and glial alterations, increased anxiety, and cognitive impairment before hippocampal amyloid deposition in PDAPP mice, model of Alzheimer's disease. Hippocampus 24, 257-269. doi: 10.1002/hipo.22219

Belanger, M., Allaman, I., and Magistretti, P. J. (2011). Brain energy metabolism: focus on astrocyte-neuron metabolic cooperation. Cell Metab. 14, 724-738. doi: 10.1016/j.cmet.2011.08.016

Bellucci, A., Westwood, A. J., Ingram, E., Casamenti, F., Goedert, M., and Spillantini, M. G. (2004). Induction of inflammatory mediators and microglial activation in mice transgenic for mutant human P301S tau protein. Am. J. Pathol. 165, 1643-1652. doi: 10.1016/s0002-9440(10)63421-9

Blair, L. J., Frauen, H. D., Zhang, B., Nordhues, B. A., Bijan, S., Lin, Y. C., et al. (2015). Tau depletion prevents progressive blood-brain barrier

\section{AUTHOR CONTRIBUTIONS}

$\mathrm{C}-\mathrm{YL}$, YY and W-NJ searched the literature and drafted the manuscript. XW and H-LZ critically revised the manuscript. All authors listed have made a substantial, direct and intellectual contribution to the work, and approved it for publication.

\section{FUNDING}

This study was supported by grants from the First Hospital of Jilin University (JDYY52015016), Norman Bethune Program of Jilin University (No. 2015335), Science and Technology Development Program of Jilin Province (20160520160JH, 172408GH01029747), as well as from the National Natural Science Foundation of China (No. 31600820, 81471216, 81500911).

damage in a mouse model of tauopathy. Acta Neuropathol. Commun. 3:8. doi: 10.1186/s40478-015-0186-2

Brancaccio, M., Patton, A. P., Chesham, J. E., Maywood, E. S., and Hastings, M. H. (2017). Astrocytes control circadian timekeeping in the suprachiasmatic nucleus via glutamatergic signaling. Neuron 93, 1420.e5-1435.e5. doi: 10.1016/j.neuron.2017.02.030

Calafate, S., Buist, A., Miskiewicz, K., Vijayan, V., Daneels, G., de Strooper, B., et al. (2015). Synaptic contacts enhance cell-to-cell tau pathology propagation. Cell Rep. 11, 1176-1183. doi: 10.1016/j.celrep.2015.04.043

Camandola, S., and Mattson, M. P. (2017). Brain metabolism in health, aging, and neurodegeneration. EMBO J. 36, 1474-1492. doi: 10.15252/EMBJ.201695810

Cao, X., Li, L. P., Wang, Q., Wu, Q., Hu, H. H., Zhang, M., et al. (2013). Astrocytederived ATP modulates depressive-like behaviors. Nat. Med. 19, 773-777. doi: $10.1038 / \mathrm{nm} .3162$

Ceyzeriat, K., Abjean, L., Carrillo-de Sauvage, M. A., Ben Haim, L., and Escartin, C. (2016). The complex STATes of astrocyte reactivity: how are they controlled by the JAK-STAT3 pathway? Neuroscience 330, 205-218. doi: 10.1016/j. neuroscience.2016.05.043

Chen, J., He, W., Hu, X., Shen, Y., Cao, J., Wei, Z., et al. (2017). A role for ErbB signaling in the induction of reactive astrogliosis. Cell Discov. 3:17044. doi: 10.1038/celldisc.2017.44

Chen, P. C., Vargas, M. R., Pani, A. K., Smeyne, R. J., Johnson, D. A., Kan, Y. W., et al. (2009). Nrf2-mediated neuroprotection in the MPTP mouse model of Parkinson's disease: critical role for the astrocyte. Proc. Natl. Acad. Sci. U S A 106, 2933-2938. doi: 10.1073/pnas.0813361106

Chen, Y., Vartiainen, N. E., Ying, W., Chan, P. H., Koistinaho, J., and Swanson, R. A. (2001). Astrocytes protect neurons from nitric oxide toxicity by a glutathione-dependent mechanism. J. Neurochem. 77, 1601-1610. doi: 10.1046/j.1471-4159.2001.00374.x

Clarke, W. E., Berry, M., Smith, C., Kent, A., and Logan, A. (2001). Coordination of fibroblast growth factor receptor 1 (FGFR1) and fibroblast growth factor-2 (FGF-2) trafficking to nuclei of reactive astrocytes around cerebral lesions in adult rats. Mol. Cell. Neurosci. 17, 17-30. doi: 10.1006/mcne.2000. 0920

Clasadonte, J., Scemes, E., Wang, Z., Boison, D., and Haydon, P. G. (2017). Connexin 43-mediated astroglial metabolic networks contribute to the regulation of the sleep-wake cycle. Neuron 95, 1365.e5-1380.e5. doi: 10.1016/j. neuron.2017.08.022

Coleman, P., Federoff, H., and Kurlan, R. (2004). A focus on the synapse for neuroprotection in Alzheimer disease and other dementias. Neurology 63, 1155-1162. doi: 10.1212/01.WNL.0000140626.48118.0a

Condello, C., Yuan, P., Schain, A., and Grutzendler, J. (2015). Microglia constitute a barrier that prevents neurotoxic protofibrillar $A \beta 42$ hotspots around plaques. Nat. Commun. 6:6176. doi: 10.1038/ncomms7176

Cregg, J. M., DePaul, M. A., Filous, A. R., Lang, B. T., Tran, A., and Silver, J. (2014). Functional regeneration beyond the glial scar. Exp. Neurol. 253, 197-207. doi: 10.1016/j.expneurol.2013.12.024 
Dani, J. W., Chernjavsky, A., and Smith, S. J. (1992). Neuronal activity triggers calcium waves in hippocampal astrocyte networks. Neuron 8, 429-440. doi: 10.1016/0896-6273(92)90271-e

de Calignon, A., Polydoro, M., Suarez-Calvet, M., William, C., Adamowicz, D. H., Kopeikina, K. J., et al. (2012). Propagation of tau pathology in a model of early Alzheimer's disease. Neuron 73, 685-697. doi: 10.1016/j.neuron.2011.11.033

DeVos, S. L., Corjuc, B. T., Oakley, D. H., Nobuhara, C. K., Bannon, R. N., Chase, A., et al. (2018). Synaptic tau seeding precedes tau pathology in human Alzheimer's disease brain. Front. Neurosci. 12:267. doi: 10.3389/fnins.2018. 00267

Di Castro, M. A., Chuquet, J., Liaudet, N., Bhaukaurally, K., Santello, M., Bouvier, D., et al. (2011). Local $\mathrm{Ca}^{2+}$ detection and modulation of synaptic release by astrocytes. Nat. Neurosci. 14, 1276-1284. doi: 10.1038/nn.2929

Ding, F., O’Donnell, J., Xu, Q., Kang, N., Goldman, N., and Nedergaard, M. (2016). Changes in the composition of brain interstitial ions control the sleep-wake cycle. Science 352, 550-555. doi: 10.1126/science.aad4821

Eclancher, F., Perraud, F., Faltin, J., Labourdette, G., and Sensenbrenner, M. (1990). Reactive astrogliosis after basic fibroblast growth factor (bFGF) injection in injured neonatal rat brain. Glia 3, 502-509. doi: 10.1002/glia. 440030609

Fellin, T., Pascual, O., Gobbo, S., Pozzan, T., Haydon, P. G., and Carmignoto, G. (2004). Neuronal synchrony mediated by astrocytic glutamate through activation of extrasynaptic NMDA receptors. Neuron 43, 729-743. doi: 10.1016/j.neuron.2004.08.011

Frik, J., Merl-Pham, J., Plesnila, N., Mattugini, N., Kjell, J., Kraska, J., et al. (2018). Cross-talk between monocyte invasion and astrocyte proliferation regulates scarring in brain injury. EMBO Rep. 5:e45294. doi: 10.15252/embr.201745294

Giaume, C., Koulakoff, A., Roux, L., Holcman, D., and Rouach, N. (2010). Astroglial networks: a step further in neuroglial and gliovascular interactions. Nat. Rev. Neurosci. 11, 87-99. doi: 10.1038/nrn2757

Goddard, D. R., Berry, M., Kirvell, S. L., and Butt, A. M. (2002). Fibroblast growth factor-2 induces astroglial and microglial reactivity in vivo. J. Anat. 200, 57-67. doi: 10.1046/j.0021-8782.2001.00002.x

Gomez-Arboledas, A., Davila, J. C., Sanchez-Mejias, E., Navarro, V., NuñezDiaz, C., Sanchez-Varo, R., et al. (2018). Phagocytic clearance of presynaptic dystrophies by reactive astrocytes in Alzheimer's disease. Glia 66, 637-653. doi: 10.1002/glia.23270

Gorlovoy, P., Larionov, S., Pham, T. T., and Neumann, H. (2009). Accumulation of tau induced in neurites by microglial proinflammatory mediators. FASEB J. 23, 2502-2513. doi: 10.1096/fj.08-123877

Guerra-Gomes, S., Sousa, N., Pinto, L., and Oliveira, J. F. (2018). Functional roles of astrocyte calcium elevations: from synapses to behavior. Front. Cell. Neurosci. 11:427. doi: 10.3389/fncel.2017.00427

Haber, M., Zhou, L., and Murai, K. K. (2006). Cooperative astrocyte and dendritic spine dynamics at hippocampal excitatory synapses. J. Neurosci. 26, 8881-8891. doi: 10.1523/JNEUROSCI.1302-06.2006

Halassa, M. M., and Haydon, P. G. (2010). Integrated brain circuits: astrocytic networks modulate neuronal activity and behavior. Annu. Rev. Physiol. 72, 335-355. doi: 10.1146/annurev-physiol-021909-135843

Han, X., Chen, M., Wang, F., Windrem, M., Wang, S., Shanz, S., et al. (2013). Forebrain engraftment by human glial progenitor cells enhances synaptic plasticity and learning in adult mice. Cell Stem Cell 12, 342-353. doi: 10.1016/j. stem.2012.12.015

Heneka, M. T., Sastre, M., Dumitrescu-Ozimek, L., Dewachter, I., Walter, J., Klockgether, T., et al. (2005). Focal glial activation coincides with increased BACE1 activation and precedes amyloid plaque deposition in APP[V717I] transgenic mice. J. Neuroinflammation 2:22. doi: 10.1186/1742-2094-2-22

Henneberger, C., Papouin, T., Oliet, S. H., and Rusakov, D. A. (2010). Longterm potentiation depends on release of D-serine from astrocytes. Nature 463, 232-236. doi: 10.1038/nature08673

Hizay, A., Seitz, M., Grosheva, M., Sinis, N., Kaya, Y., Bendella, H., et al. (2016). FGF-2 is required to prevent astrogliosis in the facial nucleus after facial nerve injury and mechanical stimulation of denervated vibrissal muscles. J. Biomed. Res. 30, 142-148. doi: 10.7555/JBR.30.20140042

Hol, E. M., Roelofs, R. F., Moraal, E., Sonnemans, M. A., Sluijs, J. A., Proper, E. A., et al. (2003). Neuronal expression of GFAP in patients with Alzheimer pathology and identification of novel GFAP splice forms. Mol. Psychiatry 8, 786-796. doi: 10.1038/sj.mp.4001379
Hoshi, A., Tsunoda, A., Yamamoto, T., Tada, M., Kakita, A., and Ugawa, Y. (2018) Altered expression of glutamate transporter-1 and water channel protein aquaporin-4 in human temporal cortex with Alzheimer's disease. Neuropathol. Appl. Neurobiol. doi: 10.1111/nan.12475 [Epub ahead of print].

Hostenbach, S., Cambron, M., D’Haeseleer, M., Kooijman, R., and De Keyser, J. (2014). Astrocyte loss and astrogliosis in neuroinflammatory disorders. Neurosci. Lett. 565, 39-41. doi: 10.1016/j.neulet.2013.10.012

Howarth, C. (2014). The contribution of astrocytes to the regulation of cerebral blood flow. Front. Neurosci. 8:103. doi: 10.3389/fnins.2014.00103

Hultman, K., Strickland, S., and Norris, E. H. (2013). The APOE varepsilon4/varepsilon4 genotype potentiates vascular fibrin(ogen) deposition in amyloid-laden vessels in the brains of Alzheimer's disease patients. J. Cereb. Blood Flow Metab. 33, 1251-1258. doi: 10.1038/jcbfm.2013.76

Iliff, J. J., Wang, M., Liao, Y., Plogg, B. A., Peng, W., Gundersen, G. A., et al. (2012). A paravascular pathway facilitates CSF flow through the brain parenchyma and the clearance of interstitial solutes, including amyloid $\beta$. Sci. Transl. Med. 4:147ra111. doi: 10.1126/scitranslmed.3003748

John, G. R., Lee, S. C., and Brosnan, C. F. (2003). Cytokines: powerful regulators of glial cell activation. Neuroscientist 9, 10-22. doi: 10.1177/1073858402 239587

Kang, W., Balordi, F., Su, N., Chen, L., Fishell, G., and Hebert, J. M. (2014). Astrocyte activation is suppressed in both normal and injured brain by FGF signaling. Proc. Natl. Acad. Sci. U S A 111, E2987-E2995. doi: 10.1073/pnas. 1320401111

Kang, K., Lee, S. W., Han, J. E., Choi, J. W., and Song, M. R. (2014). The complex morphology of reactive astrocytes controlled by fibroblast growth factor signaling. Glia 62, 1328-1344. doi: 10.1002/glia.22684

Kaufman, S. K., Thomas, T. L., Del Tredici, K., Braak, H., and Diamond, M. I. (2017). Characterization of tau prion seeding activity and strains from formaldehyde-fixed tissue. Acta Neuropathol. Commun. 5:41. doi: 10.1186/s40478-017-0442-8

Kawano, H., Oyabu, K., Yamamoto, H., Eto, K., Adaniya, Y., Kubota, K., et al. (2017). Astrocytes with previous chronic exposure to amyloid $\beta$-peptide fragment 1-40 suppress excitatory synaptic transmission. J. Neurochem. 143, 624-634. doi: 10.1111/jnc.14247

Khakh, B. S., and McCarthy, K. D. (2015). Astrocyte calcium signaling: from observations to functions and the challenges therein. Cold Spring Harb. Perspect. Biol. 7:a020404. doi: 10.1101/cshperspect.a020404

Kimelberg, H. K. (2004a). Water homeostasis in the brain: basic concepts. Neuroscience 129, 851-860. doi: 10.1016/j.neuroscience.2004.07.033

Kimelberg, H. K. (2004b). The Role of hypotheses in current research, illustrated by hypotheses on the possible role of astrocytes in energy metabolism and cerebral blood flow: from newton to now. J. Cereb. Blood Flow Metab. 24, 1235-1239. doi: 10.1097/01.wcb.0000138668.10058.8c

Kimelberg, H. K. (2010). Functions of mature mammalian astrocytes: a current view. Neuroscientist 16, 79-106. doi: 10.1177/1073858409342593

Klein, M. A., Möller, J. C., Jones, L. L., Bluethmann, H., Kreutzberg, G. W., and Raivich, G. (1997). Impaired neuroglial activation in interleukin-6 deficient mice. Glia 19, 227-233. doi: 10.1002/(sici)1098-1136(199703)19:3<227::aidglia5 > 3.0.co; $2-\mathrm{w}$

Kobayashi, E., Nakano, M., Kubota, K., Himuro, N., Mizoguchi, S., Chikenji, T., et al. (2018). Activated forms of astrocytes with higher GLT-1 expression are associated with cognitive normal subjects with Alzheimer pathology in human brain. Sci. Rep. 8:1712. doi: 10.1038/s41598-018-19442-7

Koistinaho, M., Lin, S., Wu, X., Esterman, M., Koger, D., Hanson, J., et al. (2004). Apolipoprotein E promotes astrocyte colocalization and degradation of deposited amyloid- $\beta$ peptides. Nat. Med. 10, 719-726. doi: 10.1038/nm1058

Kovac, A., Zilka, N., Kazmerova, Z., Cente, M., Zilkova, M., and Novak, M. (2011). Misfolded truncated protein tau induces innate immune response via MAPK pathway. J. Immunol. 187, 2732-2739. doi: 10.4049/jimmunol.1100216

Kovac, A., Zilkova, M., Deli, M. A., Zilka, N., and Novak, M. (2009). Human truncated tau is using a different mechanism from amyloid- $\beta$ to damage the blood-brain barrier. J. Alzheimers Dis. 18, 897-906. doi: 10.3233/JAD-20091197

Kulijewicz-Nawrot, M., Syková, E., Chvátal, A., Verkhratsky, A., and Rodríguez, J. J. (2013). Astrocytes and glutamate homoeostasis in Alzheimer's disease: a decrease in glutamine synthetase, but not in glutamate transporter-1, in the prefrontal cortex. ASN Neuro 5, 273-282. doi: 10.1042/AN20130017 
Kulijewicz-Nawrot, M., Verkhratsky, A., Chvátal, A., Syková, E., and Rodríguez, J. J. (2012). Astrocytic cytoskeletal atrophy in the medial prefrontal cortex of a triple transgenic mouse model of Alzheimer's disease. J. Anat. 221, 252-262. doi: 10.1111/j.1469-7580.2012.01536.x

Laurent, C., Buée, L., and Blum, D. (2018). Tau and neuroinflammation: what impact for Alzheimer's disease and Tauopathies? Biomed. J. 41, 21-33. doi: 10.1016/j.bj.2018.01.003

Laurent, C., Dorothee, G., Hunot, S., Martin, E., Monnet, Y., Duchamp, M., et al. (2017). Hippocampal T cell infiltration promotes neuroinflammation and cognitive decline in a mouse model of tauopathy. Brain 140, 184-200. doi: 10.1093/brain/aww270

Lécuyer, M. A., Kebir, H., and Prat, A. (2016). Glial influences on BBB functions and molecular players in immune cell trafficking. Biochim. Biophys. Acta 1862, 472-482. doi: 10.1016/j.bbadis.2015.10.004

Lenhossek, M. V. (1893). Der Feinere Bau des Nervensystems im Lichte Neuester Forschung. Berlin: Fischer's Medicinische Buchhandlung H Kornfield.

Lian, H., Yang, L., Cole, A., Sun, L., Chiang, A. C., Fowler, S. W., et al. (2015). NFkappaB-activated astroglial release of complement C3 compromises neuronal morphology and function associated with Alzheimer's disease. Neuron 85, 101-115. doi: 10.1016/j.neuron.2014.11.018

Liddelow, S. A., and Barres, B. A. (2017). Reactive astrocytes: production, function, and therapeutic potential. Immunity 46, 957-967. doi: 10.1016/j.immuni.2017. 06.006

Liddelow, S. A., Guttenplan, K. A., Clarke, L. E., Bennett, F. C., Bohlen, C. J., Schirmer, L., et al. (2017). Neurotoxic reactive astrocytes are induced by activated microglia. Nature 541, 481-487. doi: 10.1038/nature21029

Liebner, S., Dijkhuizen, R. M., Reiss, Y., Plate, K. H., Agalliu, D., and Constantin, G. (2018). Functional morphology of the blood-brain barrier in health and disease. Acta Neuropathol. 135, 311-336. doi: 10.1007/s00401-0181815-1

Liem, R. K., and Messing, A. (2009). Dysfunctions of neuronal and glial intermediate filaments in disease. J. Clin. Invest. 119, 1814-1824. doi: 10.1172/JCI38003

Liu, L., Drouet, V., Wu, J. W., Witter, M. P., Small, S. A., Clelland, C., et al. (2012). Trans-synaptic spread of tau pathology in vivo. PLoS One 7:e31302. doi: 10.1371/journal.pone.0031302

Liu, B., Teschemacher, A. G., and Kasparov, S. (2017). Neuroprotective potential of astroglia. J. Neurosci. Res. 95, 2126-2139. doi: 10.1002/jnr.24140

Logan, S., Pharaoh, G. A., Marlin, M. C., Masser, D. R., Matsuzaki, S., Wronowski, B., et al. (2018). Insulin-like growth factor receptor signaling regulates working memory, mitochondrial metabolism, and amyloid- $\beta$ uptake in astrocytes. Mol. Metab. 9, 141-155. doi: 10.1016/j.molmet.2018.01.013

Magistretti, P. J., and Allaman, I. (2015). A cellular perspective on brain energy metabolism and functional imaging. Neuron 86, 883-901. doi: 10.1016/j. neuron.2015.03.035

Maphis, N., Xu, G., Kokiko-Cochran, O. N., Jiang, S., Cardona, A., Ransohoff, R. M., et al. (2015). Reactive microglia drive tau pathology and contribute to the spreading of pathological tau in the brain. Brain 138, 1738-1755. doi: 10.1093/brain/awv081

Mathiisen, T. M., Lehre, K. P., Danbolt, N. C., and Ottersen, O. P. (2010). The perivascular astroglial sheath provides a complete covering of the brain microvessels: an electron microscopic 3D reconstruction. Glia 58, 1094-1103. doi: 10.1002/glia.20990

Menon, V. K., and Landerholm, T. E. (1994). Intralesion injection of basic fibroblast growth factor alters glial reactivity to neural trauma. Exp. Neurol. 129, 142-154. doi: 10.1006/exnr.1994.1155

Metea, M. R., and Newman, E. A. (2006). Glial cells dilate and constrict blood vessels: a mechanism of neurovascular coupling. J. Neurosci. 26, 2862-2870. doi: 10.1523/JNEUROSCI.4048-05.2006

Min, R., and Nevian, T. (2012). Astrocyte signaling controls spike timingdependent depression at neocortical synapses. Nat. Neurosci. 15, 746-753. doi: 10.1038/nn.3075

Montagne, A., Barnes, S. R., Sweeney, M. D., Halliday, M. R., Sagare, A. P., Zhao, Z., et al. (2015). Blood-brain barrier breakdown in the aging human hippocampus. Neuron 85, 296-302. doi: 10.1016/j.neuron.2014.12.032

Montagne, A., Zhao, Z., and Zlokovic, B. V. (2017). Alzheimer's disease: a matter of blood-brain barrier dysfunction? J. Exp. Med. 214, 3151-3169. doi: $10.1084 /$ jem. 20171406
Mulligan, S. J., and MacVicar, B. A. (2004). Calcium transients in astrocyte endfeet cause cerebrovascular constrictions. Nature 431, 195-199. doi: $10.1038 /$ nature 02827

Nagele, R. G., and Wegiel, J., Venkataraman, V., Imaki, H., Wang, K. C., Wegiel, J. (2004). Contribution of glial cells to the development of amyloid plaques in Alzheimer's disease. Neurobiol. Aging 25, 663-674. doi: 10.1016/j. neurobiolaging.2004.01.007

Narasimhan, S., Guo, J. L., Changolkar, L., Stieber, A., McBride, J. D., Silva, L. V., et al. (2017). Pathological tau strains from human brains recapitulate the diversity of tauopathies in nontransgenic mouse brain. J. Neurosci. 37, 11406-11423. doi: 10.1523/JNEUROSCI.1230-17.2017

Navarrete, M., Perea, G., Fernandez de Sevilla, D., Gómez-Gonzalo, M., Núñez, A., Martín, E. D., et al. (2012). Astrocytes mediate in vivo cholinergicinduced synaptic plasticity. PLoS Biol. 10:e1001259. doi: 10.1371/journal.pbio. 1001259

Nedergaard, M. (1994). Direct signaling from astrocytes to neurons in cultures of mammalian brain cells. Science 263, 1768-1771. doi: 10.1126/science.8134839

Nelson, A. R., Sweeney, M. D., Sagare, A. P., and Zlokovic, B. V. (2016). Neurovascular dysfunction and neurodegeneration in dementia and Alzheimer's disease. Biochim. Biophys. Acta 1862, 887-900. doi: 10.1016/j. bbadis.2015.12.016

Nett, W. J., Oloff, S. H., and McCarthy, K. D. (2002). Hippocampal astrocytes in situ exhibit calcium oscillations that occur independent of neuronal activity. J. Neurophysiol. 87, 528-537. doi: 10.1152/jn.00268.2001

Nilson, A. N., English, K. C., Gerson, J. E., Barton Whittle, T., Nicolas Crain, C., Xue, J., et al. (2017). Tau oligomers associate with inflammation in the brain and retina of tauopathy mice and in neurodegenerative diseases. J. Alzheimers Dis. 55, 1083-1099. doi: 10.3233/JAD-160912

Nishida, H., and Okabe, S. (2007). Direct astrocytic contacts regulate local maturation of dendritic spines. J. Neurosci. 27, 331-340. doi: 10.1523/JNEUROSCI.4466-06.2007

Oberheim, N. A., Goldman, S. A., and Nedergaard, M. (2012). Heterogeneity of astrocytic form and function. Methods Mol. Biol. 814, 23-45. doi: 10.1007/9781-61779-452-0_3

Oberheim, N. A., Takano, T., Han, X., He, W., Lin, J. H. C., Wang, F., et al. (2009). Uniquely hominid features of adult human astrocytes. J. Neurosci. 29, 3276-3287. doi: 10.1523/JNEUROSCI.4707-08.2009

Oberheim, N. A., Wang, X., Goldman, S., and Nedergaard, M. (2006). Astrocytic complexity distinguishes the human brain. Trends Neurosci. 29, 547-553. doi: 10.1016/j.tins.2006.08.004

Olabarria, M., Noristani, H. N., Verkhratsky, A., and Rodriguez, J. J. (2010). Concomitant astroglial atrophy and astrogliosis in a triple transgenic animal model of Alzheimer's disease. Glia 58, 831-838. doi: 10.1002/glia.20967

Olabarria, M., Noristani, H. N., Verkhratsky, A., and Rodriguez, J. J. (2011). Age-dependent decrease in glutamine synthetase expression in the hippocampal astroglia of the triple transgenic Alzheimer's disease mouse model: mechanism for deficient glutamatergic transmission? Mol. Neurodegener. 6:55. doi: 10.1186/1750-1326-6-55

Orr, A. G., Hsiao, E. C., Wang, M. M., Ho, K., Kim, D. H., Wang, X., et al. (2015). Astrocytic adenosine receptor $\mathrm{A}_{2 A}$ and $\mathrm{G}_{s}$-coupled signaling regulate memory. Nat. Neurosci. 18, 423-434. doi: 10.1038/nn.3930

Orre, M., Kamphuis, W., Osborn, L. M., Jansen, A. H. P., Kooijman, L., Bossers, K., et al. (2014). Isolation of glia from Alzheimer's mice reveals inflammation and dysfunction. Neurobiol. Aging 35, 2746-2760. doi: 10.1016/j.neurobiolaging. 2014.06.004

Osborn, L. M., Kamphuis, W., Wadman, W. J., and Hol, E. M. (2016). Astrogliosis: an integral player in the pathogenesis of Alzheimer's disease. Prog. Neurobiol. 144, 121-141. doi: 10.1016/j.pneurobio.2016.01.001

Parpura, V., Basarsky, T. A., Liu, F., Jeftinija, K., Jeftinija, S., and Haydon, P. G. (1994). Glutamate-mediated astrocyte-neuron signalling. Nature 369, 744-747. doi: $10.1038 / 369744 \mathrm{a} 0$

Pasti, L., Volterra, A., Pozzan, T., and Carmignoto, G. (1997). Intracellular calcium oscillations in astrocytes: a highly plastic, bidirectional form of communication between neurons and astrocytes in situ. J. Neurosci. 17, 7817-7830. doi: 10.1523/JNEUROSCI.17-20-07817.1997

Patel, A. B., Lai, J. C., Chowdhury, G. M., Hyder, F., Rothman, D. L., Shulman, R. G., et al. (2014). Direct evidence for activity-dependent glucose phosphorylation in neurons with implications for the astrocyte-to-neuron 
lactate shuttle. Proc. Natl. Acad. Sci. U S A 111, 5385-5390. doi: 10.1073/pnas. 1403576111

Perea, G., and Araque, A. (2007). Astrocytes potentiate transmitter release at single hippocampal synapses. Science 317, 1083-1086. doi: 10.1126/science.1144640

Pfrieger, F. W., and Ungerer, N. (2011). Cholesterol metabolism in neurons and astrocytes. Prog. Lipid Res. 50, 357-371. doi: 10.1016/j.plipres.2011.06.002

Porter, J. T., and McCarthy, K. D. (1996). Hippocampal astrocytes in situ respond to glutamate released from synaptic terminals. J. Neurosci. 16, 5073-5081. doi: 10.1523/JNEUROSCI.16-16-05073.1996

Rabchevsky, A. G., Weinitz, J. M., Coulpier, M., Fages, C., Tinel, M., and Junier, M. P. (1998). A role for transforming growth factor $\alpha$ as an inducer of astrogliosis. J. Neurosci. 18, 10541-10552. doi: 10.1523/JNEUROSCI.18-2410541.1998

Reilly, J. F., and Kumari, V. G. (1996). Alterations in fibroblast growth factor receptor expression following brain injury. Exp. Neurol. 140, 139-150. doi: 10.1006/exnr.1996.0124

Reilly, J. F., Maher, P. A., and Kumari, V. G. (1998). Regulation of astrocyte GFAP expression by TGF- $\beta 1$ and FGF-2. Glia 22, 202-210. doi: 10.1002/(sici)10981136(199802)22:2<202::aid-glia11>3.0.co;2-1

Robel, S., Mori, T., Zoubaa, S., Schlegel, J., Sirko, S., Faissner, A., et al. (2009). Conditional deletion of $\beta 1$-integrin in astroglia causes partial reactive gliosis. Glia 57, 1630-1647. doi: 10.1002/glia.20876

Rodríguez-Arellano, J. J., Parpura, V., Zorec, R., and Verkhratsky, A. (2016). Astrocytes in physiological aging and Alzheimer's disease. Neuroscience 323, 170-182. doi: 10.1016/j.neuroscience.2015.01.007

Roman, R. J. (2002). P-450 metabolites of arachidonic acid in the control of cardiovascular function. Physiol. Rev. 82, 131-185. doi: 10.1152/physrev. 00021.2001

Rossi, D. (2015). Astrocyte physiopathology: at the crossroads of intercellular networking, inflammation and cell death. Prog. Neurobiol. 130, 86-120. doi: 10.1016/j.pneurobio.2015.04.003

Rusakov, D. A. (2015). Disentangling calcium-driven astrocyte physiology. Nat. Rev. Neurosci. 16, 226-233. doi: 10.1038/nrn3878

Ryu, J. K., and McLarnon, J. G. (2009). A leaky blood-brain barrier, fibrinogen infiltration and microglial reactivity in inflamed Alzheimer's disease brain. J. Cell. Mol. Med. 13, 2911-2925. doi: 10.1111/j.1582-4934.2008.00434.x

Saab, A. S., Neumeyer, A., Jahn, H. M., Cupido, A., Šimek, A. A., Boele, H. J., et al. (2012). Bergmann glial AMPA receptors are required for fine motor coordination. Science 337, 749-753. doi: 10.1126/science.1221140

Sasaki, A., Kawarabayashi, T., Murakami, T., Matsubara, E., Ikeda, M., Hagiwara, H., et al. (2008). Microglial activation in brain lesions with tau deposits: comparison of human tauopathies and tau transgenic mice TgTauP301L. Brain Res. 1214, 159-168. doi: 10.1016/j.brainres.2008.02.084

Schousboe, A., Sarup, A., Bak, L. K., Waagepetersen, H. S., and Larsson, O. M. (2004). Role of astrocytic transport processes in glutamatergic and GABAergic neurotransmission. Neurochem. Int. 45, 521-527. doi: 10.1016/j.neuint.2003. 11.001

Sengillo, J. D., Winkler, E. A., Walker, C. T., Sullivan, J. S., Johnson, M., and Zlokovic, B. V. (2013). Deficiency in mural vascular cells coincides with bloodbrain barrier disruption in Alzheimer's disease. Brain Pathol. 23, 303-310. doi: 10.1111/bpa.12004

Serrano-Pozo, A., Muzikansky, A., Gómez-Isla, T., Growdon, J. H., Betensky, R. A., Frosch, M. P., et al. (2013). Differential relationships of reactive astrocytes and microglia to fibrillar amyloid deposits in Alzheimer disease. J. Neuropathol. Exp. Neurol. 72, 462-471. doi: 10.1097/NEN.0b013e3182933788

Shih, A. Y., Johnson, D. A., Wong, G., Kraft, A. D., Jiang, L., Erb, H., et al. (2003). Coordinate regulation of glutathione biosynthesis and release by Nrf2-expressing glia potently protects neurons from oxidative stress. J. Neurosci. 23, 3394-3406. doi: 10.1523/JNEUROSCI.23-08-03394.2003

Sofroniew, M. V. (2009). Molecular dissection of reactive astrogliosis and glial scar formation. Trends Neurosci. 32, 638-647. doi: 10.1016/j.tins.2009.08.002

Sofroniew, M. V. (2014). Astrogliosis. Cold Spring Harb. Perspect. Biol. 7:a020420. doi: 10.1101/cshperspect.a020420

Sofroniew, M. V., and Vinters, H. V. (2010). Astrocytes: biology and pathology. Acta Neuropathol. 119, 7-35. doi: 10.1007/s00401-009-0619-8

Sriram, K., Benkovic, S. A., Hebert, M. A., Miller, D. B., and O'Callaghan, J. P. (2004). Induction of gp130-related cytokines and activation of JAK2/STAT3 pathway in astrocytes precedes up-regulation of glial fibrillary acidic protein in the 1-methyl-4-phenyl-1,2,3,6-tetrahydropyridine model of neurodegeneration: key signaling pathway for astrogliosis in vivo? J. Biol. Chem. 279, 19936-19947. doi: 10.1074/jbc.M309304200

Stevens, B., Allen, N. J., Vazquez, L. E., Howell, G. R., Christopherson, K. S., Nouri, N., et al. (2007). The classical complement cascade mediates CNS synapse elimination. Cell 131, 1164-1178. doi: 10.1016/j.cell.2007. 10.036

Sweeney, M. D., Sagare, A. P., and Zlokovic, B. V. (2018). Blood-brain barrier breakdown in Alzheimer disease and other neurodegenerative disorders. Nat. Rev. Neurol. 14, 133-150. doi: 10.1038/nrneurol.2017.188

Takano, T., Tian, G. F., Peng, W., Lou, N., Libionka, W., Han, X., et al. (2006). Astrocyte-mediated control of cerebral blood flow. Nat. Neurosci. 9, 260-267. doi: $10.1038 / \mathrm{nn} 1623$

Takeda, S., Wegmann, S., Cho, H., DeVos, S. L., Commins, C., Roe, A. D., et al. (2015). Neuronal uptake and propagation of a rare phosphorylated highmolecular-weight tau derived from Alzheimer's disease brain. Nat. Commun. 6:8490. doi: $10.1038 /$ ncomms 9490

Tracy, T. E., and Gan, L. (2018). Tau-mediated synaptic and neuronal dysfunction in neurodegenerative disease. Curr. Opin. Neurobiol. 51, 134-138. doi: 10.1016/j.conb.2018.04.027

Ullian, E. M., Sapperstein, S. K., Christopherson, K. S., and Barres, B. A. (2001). Control of synapse number by glia. Science 291, 657-661. doi: 10.1126/science. 291.5504.657

van de Haar, H. J., Burgmans, S., Jansen, J. F., van Osch, M. J., van Buchem, M. A., Muller, M., et al. (2016a). Blood-brain barrier leakage in patients with early Alzheimer disease. Radiology 281, 527-535. doi: 10.1148/radiol. 2016152244

van de Haar, H. J., Jansen, J. F. A., van Osch, M. J. P., van Buchem, M. A., Muller, M., Wong, S. M., et al. (2016b). Neurovascular unit impairment in early Alzheimer's disease measured with magnetic resonance imaging. Neurobiol. Aging 45, 190-196. doi: 10.1016/j.neurobiolaging.2016.06.006

van Hall, G., Stromstad, M., Rasmussen, P., Jans, O., Zaar, M., Gam, C., et al. (2009). Blood lactate is an important energy source for the human brain. J. Cereb. Blood Flow Metab. 29, 1121-1129. doi: 10.1038/jcbfm.2009.35

Vargas, M. R., Johnson, D. A., Sirkis, D. W., Messing, A., and Johnson, J. A. (2008). Nrf2 activation in astrocytes protects against neurodegeneration in mouse models of familial amyotrophic lateral sclerosis. J. Neurosci. 28, 13574-13581. doi: 10.1523/JNEUROSCI.4099-08.2008

Verkhratsky, A., and Nedergaard, M. (2014). Astroglial cradle in the life of the synapse. Philos. Trans. R. Soc. Lond. B Biol. Sci. 369:20130595. doi: 10.1098/rstb. 2013.0595

Verkhratsky, A., Olabarria, M., Noristani, H. N., Yeh, C. Y., and Rodriguez, J. J. (2010). Astrocytes in Alzheimer's disease. Neurotherapeutics 7, 399-412. doi: 10.1016/j.nurt.2010.05.017

Verkhratsky, A., Rodríguez, J. J., and Steardo, L. (2014). Astrogliopathology: a central element of neuropsychiatric diseases? Neuroscientist 20, 576-588. doi: 10.1177/1073858413510208

Verkhratsky, A., Zorec, R., Rodriguez, J. J., and Parpura, V. (2016). Astroglia dynamics in ageing and Alzheimer's disease. Curr. Opin. Pharmacol. 26, 74-79. doi: 10.1016/j.coph.2015.09.011

Virchow, R. (1858). Die Cellularpathologie in Ihrer Begründung auf Physiologische und Pathologische Gewebelehre. Berlin: A Hirschwald.

Wang, Q., Jie, W., Liu, J. H., Yang, J. M., and Gao, T. M. (2017). An astroglial basis of major depressive disorder? An overview. Glia 65, 1227-1250. doi: $10.1002 /$ glia.23143

Willis, C. L., Leach, L., Clarke, G. J., Nolan, C. C., and Ray, D. E. (2004). Reversible disruption of tight junction complexes in the rat blood-brain barrier, following transitory focal astrocyte loss. Glia 48, 1-13. doi: 10.1002/glia.20049

Winter, C. G., Saotome, Y., Levison, S. W., and Hirsh, D. (1995). A role for ciliary neurotrophic factor as an inducer of reactive gliosis, the glial response to central nervous system injury. Proc. Natl. Acad. Sci. U S A 92, 5865-5869. doi: $10.1073 /$ pnas.92.13.5865

Wyss-Coray, T. (2006). Inflammation in Alzheimer disease: driving force, bystander or beneficial response? Nat. Med. 12, 1005-1015. doi: $10.1038 / \mathrm{nm} 1484$

Wyss-Coray, T., Loike, J. D., Brionne, T. C., Lu, E., Anankov, R., Yan, F., et al. (2003). Adult mouse astrocytes degrade amyloid- $\beta$ in vitro and in situ. Nat. Med. 9, 453-457. doi: 10.1038/nm838 
Yang, Y., Cui, Y., Sang, K., Dong, Y., Ni, Z., Ma, S., et al. (2018). Ketamine blocks bursting in the lateral habenula to rapidly relieve depression. Nature 554, 317-322. doi: 10.1038/nature25509

Yeh, C. Y., Vadhwana, B., Verkhratsky, A., and Rodriguez, J. J. (2011). Early astrocytic atrophy in the entorhinal cortex of a triple transgenic animal model of Alzheimer's disease. ASN Neuro 3, 271-279. doi: 10.1042/AN20110025

Yeh, C. Y., Verkhratsky, A., Terzieva, S., and Rodríguez, J. J. (2013). Glutamine synthetase in astrocytes from entorhinal cortex of the triple transgenic animal model of Alzheimer's disease is not affected by pathological progression. Biogerontology 14, 777-787. doi: 10.1007/s10522-013-9456-1

Yin, J. A., Gao, G., Liu, X. J., Hao, Z. Q., Li, K., Kang, X. L., et al. (2017). Genetic variation in glia-neuron signalling modulates ageing rate. Nature 551, 198-203. doi: 10.1038/nature24463

Yong, V. W., Moumdjian, R., Yong, F. P., Ruijs, T. C., Freedman, M. S., Cashman, N., et al. (1991). $\gamma$-interferon promotes proliferation of adult human astrocytes in vitro and reactive gliosis in the adult mouse brain in vivo. Proc. Natl. Acad. Sci. U S A 88, 7016-7020. doi: 10.1073/pnas.88.16.7016

Yoshiyama, Y., Higuchi, M., Zhang, B., Huang, S. M., Iwata, N., Saido, T. C., et al. (2007). Synapse loss and microglial activation precede tangles in a P301S tauopathy mouse model. Neuron 53, 337-351. doi: 10.1016/j.neuron. 2007.01.010

Zamanian, J. L., Xu, L., Foo, L. C., Nouri, N., Zhou, L., Giffard, R. G., et al. (2012). Genomic analysis of reactive astrogliosis. J. Neurosci. 32, 6391-6410. doi: 10.1523/JNEUROSCI.6221-11.2012

Zenaro, E., Piacentino, G., and Constantin, G. (2017). The blood-brain barrier in Alzheimer's disease. Neurobiol. Dis. 107, 41-56. doi: 10.1016/j.nbd.2016.07.007
Zhang, J., and Liu, Q. (2015). Cholesterol metabolism and homeostasis in the brain. Protein Cell 6, 254-264. doi: 10.1007/s13238-014-0131-3

Zhao, Z., Nelson, A. R., Betsholtz, C., and Zlokovic, B. V. (2015). Establishment and dysfunction of the blood-brain barrier. Cell 163, 1064-1078. doi: 10.1016/j. cell.2015.10.067

Zielke, H. R., Zielke, C. L., and Baab, P. J. (2009). Direct measurement of oxidative metabolism in the living brain by microdialysis: a review. J. Neurochem. 109, 24-29. doi: 10.1111/j.1471-4159.2009.05941.x

Zlokovic, B. V. (2008). The blood-brain barrier in health and chronic neurodegenerative disorders. Neuron 57, 178-201. doi: 10.1016/j.neuron.2008. 01.003

Zonta, M., Angulo, M. C., Gobbo, S., Rosengarten, B., Hossmann, K. A., Pozzan, T., et al. (2003). Neuron-to-astrocyte signaling is central to the dynamic control of brain microcirculation. Nat. Neurosci. 6, 43-50. doi: 10.1038/nn980

Conflict of Interest Statement: The authors declare that the research was conducted in the absence of any commercial or financial relationships that could be construed as a potential conflict of interest.

Copyright (C) 2018 Liu, Yang, Ju, Wang and Zhang. This is an open-access article distributed under the terms of the Creative Commons Attribution License (CC BY). The use, distribution or reproduction in other forums is permitted, provided the original author(s) and the copyright owner(s) are credited and that the original publication in this journal is cited, in accordance with accepted academic practice. No use, distribution or reproduction is permitted which does not comply with these terms. 